\title{
Simple Harmonics Compensation Method for Smart Charger with Constant DC-Capacitor Voltage-Control for Electric Vehicles in Single-Phase Three-Wire Distribution Feeders
}

\author{
Fuka Ikeda* \\ Member, \\ Toshihiko Tanaka*a) \\ Fellow \\ Hiroaki Yamada** $^{* *}$ Member, Masayuki Okamoto* ${ }^{*}$ Member
}

(Manuscript received Aug. 2, 2017, revised June 16, 2018)

\begin{abstract}
This paper discusses harmonic current compensation of the constant dc-capacitor voltage-control (CDCVC)-based strategy for smart charger for electric vehicles (EVs) in single-phase three-wire distribution feeders (SPTWDFs) under distorted load current conditions. The basic principle of the CDCVC-based harmonics compensation strategy under distorted load current conditions is discussed in detail. The instantaneous power flowing into the three-leg pulse-width modulated (PWM) rectifier, which acts as a smart charger, shows that the CDCVC-based strategy achieves balanced and sinusoidal source currents with a unity power factor (PF). The CDCVC-based harmonics compensation strategy does not require any calculation blocks of fundamental reactive, unbalanced active, and harmonic currents. Thus, the authors propose a simplified algorithm to compensate for reactive, unbalanced active, and harmonic currents. Simulation and experimental results demonstrate that balanced and sinusoidal source currents with a unity PF in SPTWDFs are obtained on the secondary side of the pole-mounted distribution transformer during both the battery-charging and battery-discharging operations in EVs, compensating the reactive, unbalanced active, and harmonic currents.
\end{abstract}

Keywords: single-phase three-wire distribution feeders, harmonics compensation, constant dc-capacitor voltage control, three-leg PWM rectifier, single-phase PLL circuit, single-phase $d-q$ coordinates

\section{Introduction}

Smart meters are currently installed for domestic consumers in areas serviced by the Tokyo Electric Power Company and the Kansai Electric Power Company ${ }^{(1)}$. These smart meters report the power consumption conditions of each domestic consumer to the electric power companies. Power consumption conditions, however, are not yet reported commercially. It is obvious that household electricity prices associated with high-quality power consumption should be lower than those for the consumers with low-quality power consumption. Thus, in the near future, each domestic consumer will take responsibility for improving the quality of their own power consumption. Electric vehicles (EVs), such as the Mitsubishi i-MiEV, a five-door hatchback kei car, and the Nissan LEAF, a medium-sized five-door hatchback car, are now commercially available in Japan. The lithium-ion batteries equipped in the $\mathrm{i}-\mathrm{MiEV}$ can store the electric energy of $16 \mathrm{kWh}$, whereas the maximum stored energy in the LEAF is $30 \mathrm{kWh}$. These EVs are highly mobile with this stored energy, so the concept of injecting power stored in EVs into the grid or home (Vehicle-to-Grid or Vehicle-to-Home) was proposed $^{(2)-(5)}$. A pulse-width modulated (PWM) rectifier with

a) Correspondence to: Toshihiko Tanaka. E-mail: totanaka@ yamaguchi-u.ac.jp

* National Institute of Technology, Ube College

2-14-1, Tokiwadai, Ube, Yamaguchi 755-8555, Japan

** Yamaguchi University

2-16-1, Tokiwadai, Ube, Yamaguchi 755-8611, Japan a bidirectional dc-dc converter was used with a photovoltaic (PV) system ${ }^{(6)}$, and control and power management of the PV system were discussed. Various studies analyzing the value and potential impact on the utility grid were reported ${ }^{(7)-(9)}$, in which the analysis of the reactive power operation in a charger was described in detail. The operation modes of the proposed battery charger were divided into quadrants based on the active and reactive powers on the ac side. In addition, the control method, dc-capacitor design, ac inductor design, and loss evaluation were discussed. In Japan, singlephase three-wire distribution feeders (SPTWDFs) with polemounted distribution transformers (PMDTs) are used for domestic consumers. If the charger in ${ }^{(7)-(9)}$ is connected to SPTWDFs, perfect reactive power compensation for each feeder with a unity power factor (PF) cannot be achieved on the low-voltage side. Thus, unbalanced secondary-side source-current conditions remain on the secondary side of the PMDT. It is known that these conditions increase losses in PMDTs. There are a large number of PMDTs in Japan, so the total economic losses caused by unbalanced secondaryside source-currents conditions are great. Balancing the currents in the two feeders is effective for balancing the feeder voltages and reducing the losses.

It is also obvious that domestic consumers should be responsible for the loss compensation in PMDTs with improved power quality, which can report the power consumption conditions of each domestic consumer to the electric power companies. The present authors, thus, proposed a smart charger for EVs with a power quality compensator in 


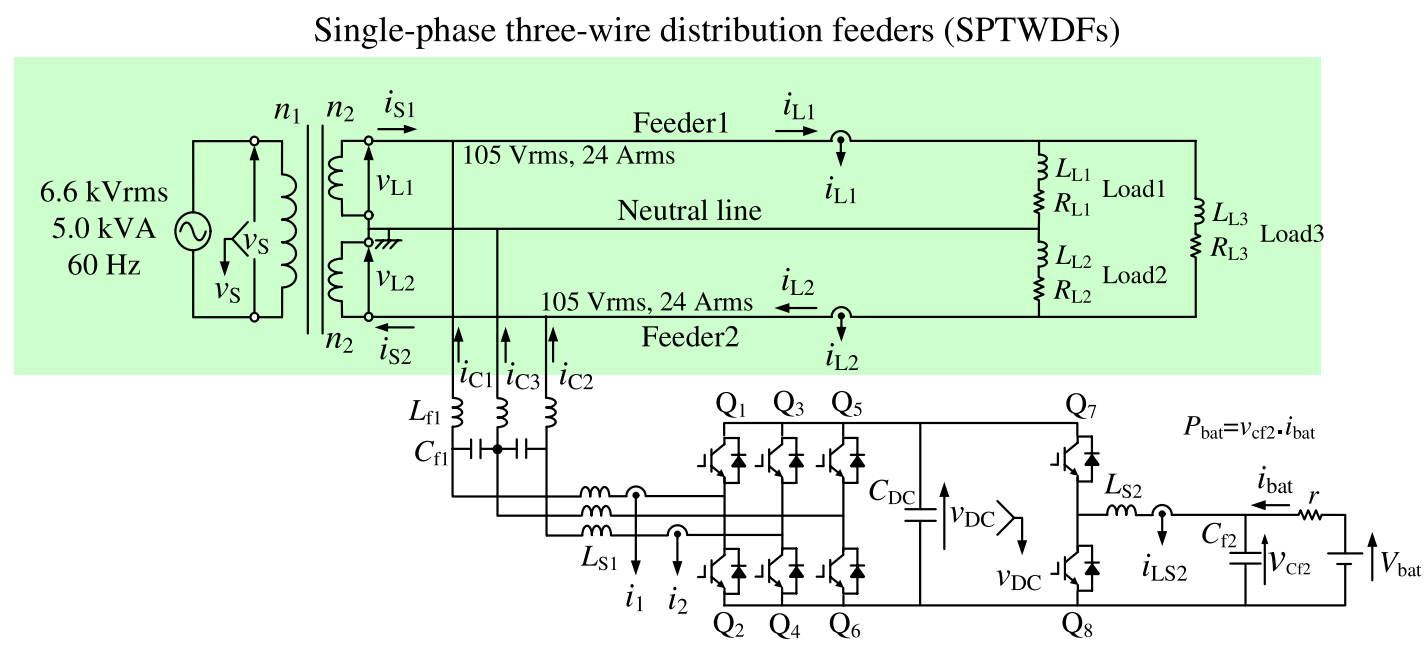

Fig. 1. Power circuit diagram of the previously proposed smart charger for electric vehicles (EVs) with a power quality compensator in single-phase three-wire distribution feeders (SPTWDFs) ${ }^{(10)}$

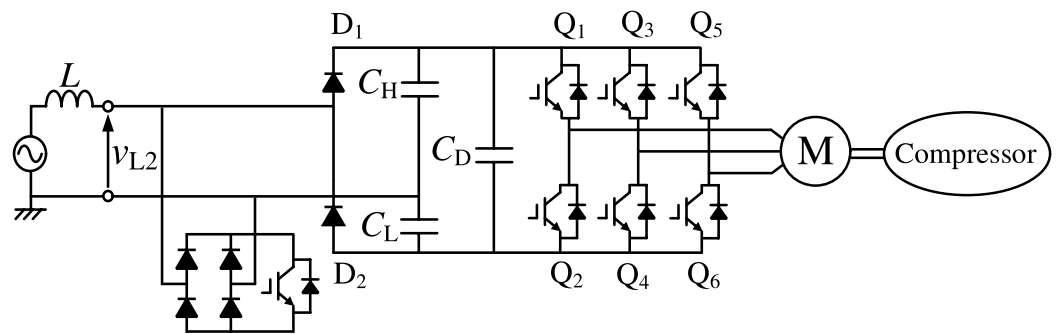

Fig. 2. Power circuit diagram of motor drive system used in air conditioners ${ }^{(11)}$

SPTWDFs ${ }^{(10)}$. Figure 1 shows a power circuit diagram of the previously proposed smart charger for EVs with a power quality compensator. The proposed smart charger comprises four-leg insulated-gate bipolar transistors (IGBTs). The first three legs consisting of $\mathrm{Q}_{1}, \mathrm{Q}_{2}, \mathrm{Q}_{3}, \mathrm{Q}_{4}, \mathrm{Q}_{5}$, and $\mathrm{Q}_{6}$ are used for a three-leg PWM rectifier. The first and second legs are connected to Feeder1 and Feeder2, respectively. The third leg is connected to the neutral line, and is an advantage of the proposed smart charger compared with those proposed in (7)-(9). This third leg allows the PWM rectifier to compensate reactive and unbalanced active currents in SPTWDFs by canceling the neutral line current. The fourth leg, comprising $\mathrm{Q}_{7}$ and $\mathrm{Q}_{8}$, acts as a bidirectional dc-dc converter for both the battery-charging and battery-discharging operations in EVs. For the control strategy of the three-leg PWM rectifier in Fig. 1, only a constant dc-capacitor voltage control (CDCVC), which is commonly used in active powerline conditioners, is used. Simulation and experimental results demonstrated that the CDCVC-based control strategy achieves the balanced source currents with a unity PF on the source side of SPTWDFs during both the battery-charging and battery-discharging operations in EVs. In the SPTWDs in 1, large-capacity consumer electronics are connected to Feeder 1 and Feeder 2 as Load3, and their voltage rating is 210 Vrms. Typical large-capacity consumer electronics include air conditioners for large rooms and induction heating $(\mathrm{IH})$ cookers. In these consumer electronics, the supplied ac voltage is converted to dc. Subsequently, power is supplied to the final target load with inverters. Thus, diode rectifiers, which are nonlinear loads, are included in air conditioners and IH cookers. Small-capacity consumer electronics are connected to each feeder with a neutral line, and their voltage rating is $105 \mathrm{Vrms}$. Typical small-capacity consumer electronics include air conditioners for small rooms, refrigerators, personal computers, liquid crystal display televisions, and LED illuminators. In small-capacity air conditioners and refrigerators, inverters are used to supply the power to the final target load. Diode rectifiers are, thus, included in the small-capacity air conditioners and refrigerators. For example, Fig. 2 shows a power circuit diagram of a motor drive system, which is used to control the rotation speed of the compressor in air conditioners ${ }^{(11)}$. The diode rectifiers generate harmonic currents that are injected into the utility-grid. Liquid crystal display televisions and LED illuminators consume dc power, and include diode rectifiers. Thus, modern consumer electronics include diode rectifiers, which are nonlinear loads. However, only the RL linear loads were connected to Feeder1 and Feeder2 in Fig. 1. Harmonic currents compensation of the CDCVC-based strategy for the smart charger for EVs in SPTWDFs considering modern consumer electronics, which include diode rectifiers, should be considered for practical uses of the smart charger with the CDCVC-based strategy for EVs in SPTWDFs.

This paper presents reactive, unbalanced active, and harmonic currents compensation using the CDCVC- based strategy for a smart charger in SPTWDFs under distorted load current conditions. The basic principle of the previously proposed CDCVC-based strategy for smart chargers is discussed in detail. The instantaneous power flowing into the smart charger shows that the previously proposed 

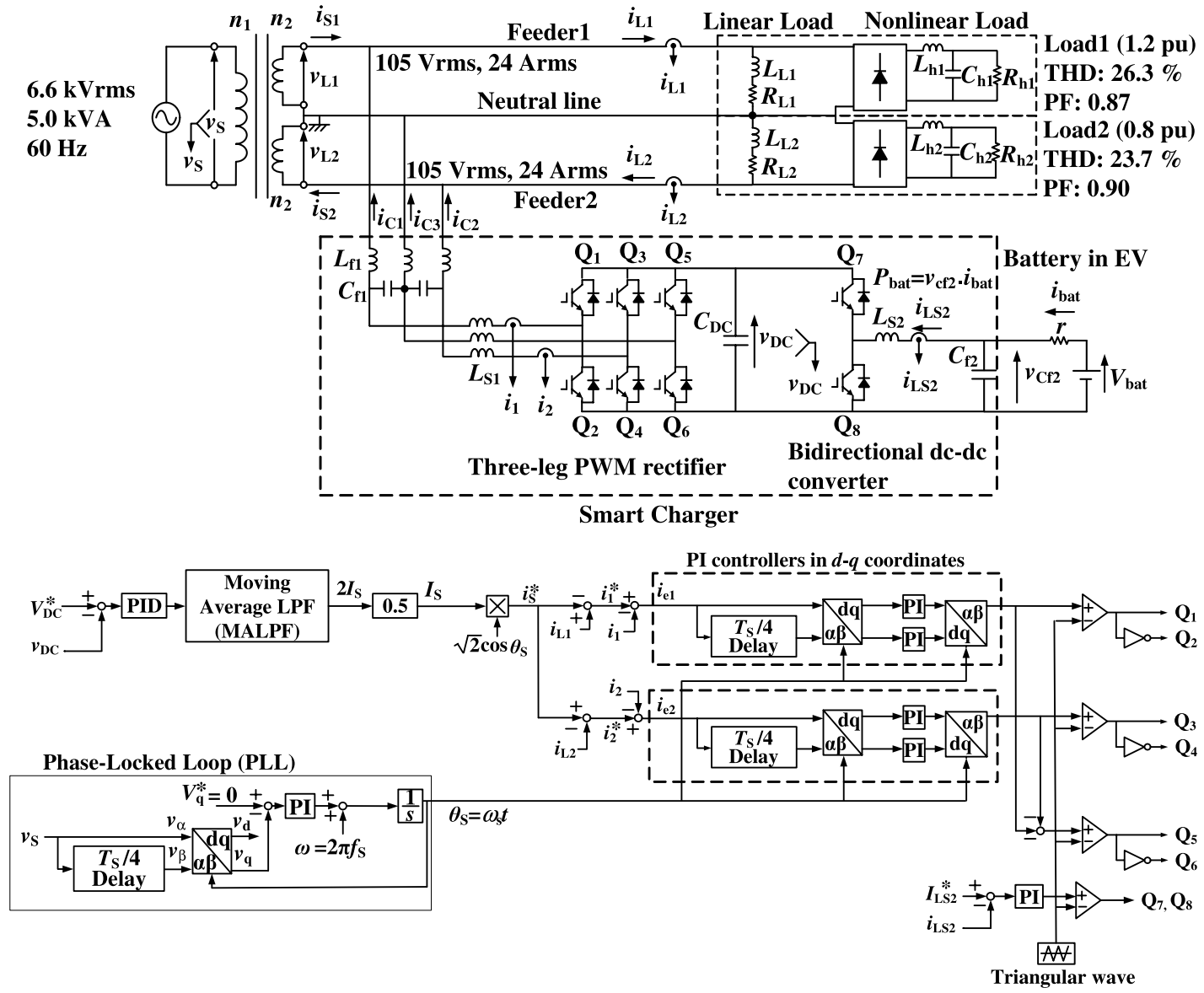

Fig. 3. Circuit diagram of proposed smart charger for EVs with nonlinear loads in SPTWDFs

CDCVC-based strategy can compensate fundamental reactive, unbalanced active, and harmonic currents on the source side. The balanced and sinusoidal source currents with a unity PF are achieved using only the CDCVC-based strategy, which is commonly used in active power-line conditioners. A digital computer simulation is implemented to confirm the validity and high practicability of the CDCVC-based strategy under unbalanced and distorted load current conditions. A reduced-scale prototype experimental model is constructed and tested. Simulation and experimental results demonstrate that balanced and sinusoidal source currents with a unity PF are achieved on the secondary side of the PMDT during the battery-charging and battery-discharging operations in EVs, compensating the fundamental reactive, unbalanced active, and harmonic currents. Simulation and experimental results also demonstrate that balanced and sinusoidal source currents with unity PF are achieved even though EVs are not connected to the smart charger.

\section{Constant DC-Capacitor Voltage-Control-Based Strategy for Harmonics Compensation of Smart Charger}

Figure 3 shows a circuit diagram of the proposed smart charger with RL linear and nonlinear loads. As described in Introduction, modern consumer electronics include power electronic circuits. Diode rectifiers, which are nonlinear loads, are used in these modern consumer electronics. Thus, nonlinear loads are connected in parallel to the RL linear loads in Fig. 3. The voltage rating of the PMDT is $6.6 \mathrm{kVrms}$, $5.0 \mathrm{kVA}$, and $60 \mathrm{~Hz}$ on the primary side, and $105 \mathrm{Vrms}$ on the secondary side. Thus, the current rating of the Feeder1 and Feeder 2 currents is 24 Arms. Diode rectifiers are included in modern consumer electronics. Thus, diode rectifiers in addition to linear loads are connected to each feeder with a neutral line. These diode rectifiers represent modern consumer electronics in SPTWDFs. The total harmonic distortion (THD) values were decided with IEC61000-3-4 ${ }^{(12)}$. For the battery model, a dc voltage source of $360 \mathrm{Vdc}$ is used. For the control algorithm of the three-leg PWM rectifier, the CDCVC-based strategy is used ${ }^{(10)}$. A proportional-integral (PI) controller was used in the CDCVC block ${ }^{(10)}$. In this paper, a proportional-integral-derivative (PID) controller is used to improve the response of the CDCVC- based control strategy because harmonic currents are included in addition to fundamental reactive and unbalanced active components of the load currents $i_{\mathrm{L} 1}$ and $i_{\mathrm{L} 2}$. In three-phase circuits, some control strategies for active power-line conditioners are based on instantaneous active-reactive power theory, the so-called " $p q$ theory," which was originally proposed by Prof. Akagi et al. ${ }^{(13)-(17)}$. The instantaneous symmetrical component theory method, the sample and hold circuit method, and the $d$ $q$ transformation-based method are also used for the calculation of the reference compensation currents ${ }^{(18)-(20)}$. Singlephase $p q$ theory was proposed for single-phase active power line conditioners ${ }^{(21)}$. In this method, the instantaneous activereactive power calculation block is also included. However, 
in Fig. 3, no calculation blocks of the reactive, unbalanced active, and harmonic components of the load currents are necessary. Thus, the authors provide the simplified algorithm for the smart charger. This simple control algorithm achieves balanced and sinusoidal source currents with a unity PF.

Here, the reactive, unbalanced active, and harmonic current compensation using the CDCVC-based strategy for smart charger in SPTWDFs under distorted load current conditions is discussed. Let us assume that the source voltage $v_{\mathrm{S}}$ and the secondary-side voltages $v_{\mathrm{L} 1}$ and $v_{\mathrm{L} 2}$ are purely sinusoidal. Then, $v_{\mathrm{S}}, v_{\mathrm{L} 1}$, and $v_{\mathrm{L} 2}$ are expressed as

$$
\begin{aligned}
v_{\mathrm{S}} & =\sqrt{2} V_{\mathrm{S}} \cos \omega_{\mathrm{S}} t, \\
v_{\mathrm{L}} & =v_{\mathrm{L} 1}=v_{\mathrm{L} 2} \\
& =\sqrt{2} V_{\mathrm{L}} \cos \omega_{\mathrm{S}} t .
\end{aligned}
$$

The load currents $i_{\mathrm{L} 1}$ and $i_{\mathrm{L} 2}$ in Feeder1 and Feeder2 are also expressed as

$$
\begin{aligned}
i_{\mathrm{L} 1}= & \sqrt{2} I_{L 11} \cos \left(\omega_{\mathrm{S}} t-\phi_{\mathrm{L} 11}\right) \\
& +\sqrt{2} \sum_{n=2}^{\infty} I_{\mathrm{L} 1 n} \cos \left(n \omega_{\mathrm{S}} t-\phi_{\mathrm{L} 1 n}\right) \\
i_{\mathrm{L} 2}= & \sqrt{2} I_{L 21} \cos \left(\omega_{\mathrm{S}} t-\phi_{\mathrm{L} 21}\right) \\
& +\sqrt{2} \sum_{n=2}^{\infty} I_{\mathrm{L} 2 n} \cos \left(n \omega_{\mathrm{S}} t-\phi_{\mathrm{L} 2 n}\right) .
\end{aligned}
$$

When the reactive, unbalanced active, and harmonic components of the load currents $i_{\mathrm{L} 1}$ and $i_{\mathrm{L} 2}$ are compensated on the secondary side by a smart charger using the CDCVC-based strategy, the source currents $i_{\mathrm{S} 1}$ and $i_{\mathrm{S} 2}$ are balanced and sinusoidal with a unity PF. Thus, the desired source current $i_{\mathrm{S}}^{*}$, which is $i_{\mathrm{S} 1}$ and $i_{\mathrm{S} 2}$, in Feeder1 and Feeder2, is expressed as

$$
\begin{aligned}
i_{\mathrm{S}}^{*} & =i_{\mathrm{S} 1}=i_{\mathrm{S} 2} \\
& =\sqrt{2} I_{\mathrm{S}} \cos \omega_{\mathrm{S}} t
\end{aligned}
$$

where $I_{\mathrm{S}}$ is the root-mean square (RMS) value of $i_{\mathrm{S}}^{*}, i_{\mathrm{S} 1}^{*}$, and $i_{\mathrm{S} 2}^{*}$. The reference values $i_{\mathrm{C} 1}^{*}, i_{\mathrm{C} 2}^{*}$, and $i_{\mathrm{C} 3}^{*}$ of the three-leg $\mathrm{PWM}$ rectifier are given by

$$
\begin{aligned}
& i_{\mathrm{C} 1}^{*}=i_{\mathrm{L} 1}-i_{\mathrm{S} 1}, \\
& i_{\mathrm{C} 2}^{*}=-i_{\mathrm{L} 2}+i_{\mathrm{S} 2}, \\
& i_{\mathrm{C} 3}^{*}=-\left(i_{\mathrm{C} 1}^{*}+i_{\mathrm{C} 2}^{*}\right)
\end{aligned}
$$

The instantaneous power $p_{\mathrm{SC}}$ flowing into the smart charger, which is the three-leg PWM rectifier, is given by

$$
\begin{aligned}
p_{\mathrm{SC}}= & -v_{\mathrm{L} 1} \cdot i_{\mathrm{C} 1}+v_{\mathrm{L} 2} \cdot i_{\mathrm{C} 2} \\
= & V_{\mathrm{L}}\left[\left(-I_{\mathrm{L} 11} \cos \phi_{\mathrm{L} 11}-I_{\mathrm{L} 21} \cos \phi_{\mathrm{L} 21}+2 I_{\mathrm{S}}\right)\right. \\
& +\left(-I_{\mathrm{L} 11} \cos \phi_{\mathrm{L} 11}-I_{\mathrm{L} 21} \cos \phi_{\mathrm{L} 21}+2 I_{\mathrm{S}}\right) \cos 2 \omega_{\mathrm{S}} t \\
& +\left(-I_{\mathrm{L} 11} \sin \phi_{\mathrm{L} 11}-I_{\mathrm{L} 21} \sin \phi_{\mathrm{L} 21}\right) \sin 2 \omega_{\mathrm{S}} t \\
& +\sum_{n=2}^{\infty}\left(-I_{\mathrm{L} 1 n} \cos \phi_{\mathrm{L} 1 n}-I_{\mathrm{L} 2 n} \cos \phi_{\mathrm{L} 2 n}\right) . \\
& \left\{\cos (n+1) \omega_{\mathrm{S}} t+\cos (n-1) \omega_{\mathrm{S}} t\right\} \\
& +\sum_{n=2}^{\infty}\left(-I_{\mathrm{L} 1 n} \sin \phi_{\mathrm{L} 1 n}-I_{\mathrm{L} 2 n} \sin \phi_{\mathrm{L} 2 n}\right) . \\
& \left.\left\{\sin (n+1) \omega_{\mathrm{S}} t+\sin (n-1) \omega_{\mathrm{S}} t\right\}\right] . \cdots \ldots(5)
\end{aligned}
$$

If the dc-capacitor voltage $v_{\mathrm{DC}}$ is constant by the CDCVC in Fig. 3, the mean value of $\bar{p}_{\mathrm{SC}}$ should be $P_{\text {bat }}$ because the power charged to or discharged from the battery is exchanged to the utility through the dc-capacitor $C_{\mathrm{DC}}$. Thus, $\bar{p}_{\mathrm{SC}}$ is given by

$$
\begin{aligned}
& \bar{p}_{\mathrm{SC}}=V_{\mathrm{L}}\left(-I_{\mathrm{L} 11} \cos \phi_{\mathrm{L} 11}-I_{\mathrm{L} 21} \cos \phi_{\mathrm{L} 21}+2 I_{\mathrm{S}}\right) \\
&=P_{\text {bat }} . \\
& \ldots \ldots \ldots \cdots \cdots
\end{aligned}
$$

The mean value $\bar{p}_{\mathrm{SC}}$ of the instantaneous power $p_{\mathrm{SC}}$ flowing into the smart charger equals $P_{\text {bat }}$ in (6). Thus, the RMS value $I_{\mathrm{S}}$ of $i_{\mathrm{S}}^{*}, i_{\mathrm{S} 1}$, and $i_{\mathrm{S} 2}$ in (3) is expressed as

$$
I_{\mathrm{S}}=\frac{I_{\mathrm{L} 11} \cos \phi_{\mathrm{L} 11}+I_{\mathrm{L} 21} \cos \phi_{\mathrm{L} 21}}{2}+\frac{P_{\mathrm{bat}}}{2 V_{\mathrm{L}}} \text {. }
$$

In the control circuit in Fig. 3, the desired source current $i_{\mathrm{S}}^{*}$, which are $i_{\mathrm{S} 1}$ and $i_{\mathrm{S} 2}$, is generated by the output value $2 I_{\mathrm{S}}$ of the PID controller with $\sqrt{2} \cos \theta_{\mathrm{s}}$. Thus, (7) has an important implication that the mean value $\bar{p}_{\mathrm{SC}}$ of $p_{\mathrm{SC}}$ is $P_{\text {bat }}$ when the output value of the PID controller in the CDCVC equals $2 I_{\mathrm{S}}$. With the CDCVC-based strategy, balanced and sinusoidal source currents with a unity $\mathrm{PF}$, which are expressed by (3), are achieved on the secondary side of the PMDT when charging or discharging the power $P_{\text {bat }}$ from/to the utility grid, even though the load currents $i_{\mathrm{L} 1}$ and $i_{\mathrm{L} 2}$ are unbalanced and heavily distorted. The dc-capacitor voltage $v_{\mathrm{DC}}$ of the three-leg PWM rectifier is detected, and then the difference $\Delta v_{\mathrm{DC}}$ between the reference value $v_{\mathrm{DC}}^{*}$ and the detected $v_{\mathrm{DC}}$ is amplified by the PID controller. A moving average LPF is used to remove the $2 \omega_{\mathrm{S}}$ components, where $\omega_{\mathrm{S}}$ is the angular frequency of the source voltage. After the moving average LPF, the effective value $2 I_{\mathrm{S}}$ of the source currents $i_{\mathrm{S} 1}$ and $i_{\mathrm{S} 2}$ is calculated. The reference active component $i_{\mathrm{S}}^{*}$ is obtained by multiplying $I_{\mathrm{S}}$ with $\sqrt{2} \cos \theta_{\mathrm{s}}$, where a single-phase phase-locked loop (PLL) is used to detect the electric angle $\theta_{\mathrm{S}}=\omega_{\mathrm{S}} t$ of $v_{\mathrm{S}}{ }^{(22)(23)}$. This $i_{\mathrm{S}}^{*}$ is equal to that stated in (3). The source voltage $v_{\mathrm{S}}$ is detected in the single-phase PLL. This $v_{\mathrm{S}}$ corresponds to the detected $\alpha$-phase component $v_{\alpha}$. The component delayed by $T_{\mathrm{S}} / 4$ corresponds to the $\beta$-phase component $v_{\beta}$. Then, $v_{\alpha}$ and $v_{\beta}$ are transformed to $v_{\mathrm{d}}$ and $v_{\mathrm{q}}$ in $d$ - $q$ coordinates using the generated electric angle $\theta_{\mathrm{S}}$, respectively. When $v_{\mathrm{q}}$ is controlled to zero by a PI controller in $d-q$ coordinates, it is possible to generate an electrical reference angle $\theta_{\mathrm{S}}$ that is synchronized with $v_{\mathrm{S}}$, which has angular frequency $\omega_{\mathrm{S}}$. Finally, by subtracting the calculated $i_{\mathrm{S}}^{*}$ from the detected load currents $i_{\mathrm{L} 1}$ and $i_{\mathrm{L} 2}$, the reference values $i_{1}^{*}, i_{2}^{*}$, and $i_{3}^{*}$ for the three-leg PWM rectifier are calculated as

$$
\begin{aligned}
& i_{1}^{*}=i_{\mathrm{L} 1}-i_{\mathrm{S}}^{*}, \\
& i_{2}^{*}=-i_{\mathrm{L} 2}+i_{\mathrm{S}}^{*}, \\
& i_{3}^{*}=-\left(i_{1}^{*}+i_{2}^{*}\right),
\end{aligned}
$$

It is well known that a steady-state error remains when a current controller using a triangle intersection method based PI controller in a single-phase PWM rectifier is used. To avoid this steady-state error, an interesting current feedback control scheme in $d-q$ coordinates for single-phase circuits was proposed ${ }^{(24)}$. Numerical shift-resistors are used to obtain the imaginary component, which is orthogonal to the actually detected signal. The actually detected signal and the 
imaginary component are transformed into $d$ - $q$ coordinates; subsequently, the current controller in single-phase circuits is achieved. For more details, see the literature (24).

The basic principle of the PI controllers in $d$ - $q$ coordinates in Fig. 3 is introduced herein. The switching frequency $f_{\mathrm{S}}$ of the three-leg PWM rectifier is $12 \mathrm{kHz}$. The number of sampled data over a cycle $T_{\mathrm{S}}$ of the fundamental frequency of the source voltage $v_{\mathrm{S}}$ is 200 points, with the frequency of the source voltage $v_{\mathrm{S}}$ being $60 \mathrm{~Hz}$. The number of data points for the quarter cycle for the fundamental component is 50 . Thus, synchronization of the $T_{\mathrm{S}} / 4$ delay block to the source voltage $v_{\mathrm{S}}$ is achieved. For example, in Fig. 3, to control the first-leg current $i_{1}$, the difference $i_{\mathrm{e} 1}$ between the reference value $i_{1}^{*}$ and the detected current $i_{1}$ is calculated. This $i_{\mathrm{e} 1}$ corresponds to the $\alpha$-phase component in $\alpha-\beta$ coordinates. Subsequently, $i_{\mathrm{e} 1}$ is continuously stored in a one-dimensional array in the half-cycle period of the source voltage $v_{\mathrm{S}}$, where the data points of $i_{\mathrm{e} 1}$ are 100 . The $\beta$-phase component $i_{\mathrm{e} 1 \beta}$ is generated with the stored $i_{\mathrm{e} 1}$ in the one-dimensional array, where the data point for the stored $i_{\mathrm{e} 1}$ is delayed by 50 points. The difference $i_{\mathrm{e} 1}$ and the generated $i_{\mathrm{e} 1 \beta}$ are transformed to $i_{d 1}^{*}$ and $i_{q 1}^{*}$ in $d-q$ coordinates, respectively. These $i_{d 1}^{*}$ and $i_{q 1}^{*}$ are amplified by PI controllers in $d$ - $q$ coordinates. The amplified differences are retransformed into $\alpha-\beta$ coordinates; subsequently, the triangle intersection method is used to control the output current $i_{1}$.

Profs. Saitou and Shimizu proposed a novel current feedback control method for single-phase circuits in $d-q$ coordinates, in which a Hilbert transform is used to generate the orthogonal component to the originally detected current ${ }^{(25)}$. In their method, Hilbert transform is implemented by numerical differentiation. In Fig. 3 , the $\beta$-phase component $i_{\mathrm{e} 1 \beta}$, which is orthogonal to the $\alpha$-phase component $i_{\mathrm{e} 1}$, is generated by the stored $i_{\mathrm{e} 1}$ in the one-dimensional array, where the data point for the $\beta$-phase component $i_{\mathrm{e} 1 \beta}$ is delayed by 50 data points with the stored $i_{\mathrm{e} 1}$. Thus, the feedback control in $d-q$ coordinates with a numerical $T_{\mathrm{S}} / 4$ delay block is simpler.

The fourth leg, $\mathrm{Q}_{7}$ and $\mathrm{Q}_{8}$, are used as a bidirectional dc$\mathrm{dc}$ converter. For the battery-charging operation, $\mathrm{Q}_{7}$ is used to control the inductor current $i_{\mathrm{LS} 2}$ while $\mathrm{Q}_{8}$ is off. Only the diode in $\mathrm{Q}_{8}$ is used. Thus, the fourth leg performs in a buck chopper. The inductor current $i_{\mathrm{LS} 2}$ is detected. Then, the deference between the reference value $I_{\mathrm{LS} 2}^{*}$ and the detected inductor current $i_{\mathrm{LS} 2}$ is amplified; subsequently, the triangle intersection method is used to generate the control signal for $\mathrm{Q}_{7}$ to control the inductor current $i_{\mathrm{LS} 2}$. For the battery-discharging operation, $\mathrm{Q}_{8}$ is used to to control the inductor current $i_{\mathrm{LS} 2}$ while $\mathrm{Q}_{7}$ is off. Only the diode in $\mathrm{Q}_{7}$ is used. Thus, the fourth leg performs in a boost chopper. The inductor current $i_{\mathrm{LS} 2}$ is detected. The deference between the reference value $I_{\mathrm{LS} 2}^{*}$ and the detected inductor current $i_{\mathrm{LS} 2}$ is amplified; subsequently, the triangle intersection method is used to generate the control signal for $\mathrm{Q}_{8}$ to control the inductor current $i_{\mathrm{LS} 2}$.

\section{Simulation Results}

The validity and high practicability of the proposed control algorithm for the proposed smart charger are confirmed by digital computer simulation using PSIM software. The unbalanced ratio between Feeder 1 and Feeder2 is defined by
Table 1. Circuit Constants for Fig. 3

\begin{tabular}{c|c|c}
\hline Item & Symbol & Value \\
\hline \hline Filter inductor & $L_{\mathrm{f}}$ & $0.46 \mathrm{mH}$ \\
\hline Filter capacitor & $C_{\mathrm{f}}$ & $10.4 \mu \mathrm{F}$ \\
\hline $\begin{array}{c}\text { Switching inductor } \\
\text { for three-leg inverter }\end{array}$ & $L_{\mathrm{S} 1}$ & $1.0 \mathrm{mH}$ \\
\hline dc capacitor & $C_{\mathrm{DC}}$ & $3000 \mu \mathrm{F}$ \\
\hline dc-capacitor voltage & $V_{\mathrm{DC}}^{*}$ & $385 \mathrm{Vdc}$ \\
\hline $\begin{array}{c}\text { Switching inductor } \\
\text { for dc-dc converter }\end{array}$ & $L_{\mathrm{S} 2}$ & $3.3 \mathrm{mH}$ \\
\hline $\begin{array}{c}\text { Filter capacitor } \\
\text { for dc-dc converter }\end{array}$ & $C_{\mathrm{f} 2}$ & $1000 \mu \mathrm{F}$ \\
\hline Battery voltage & $V_{\mathrm{bat}}$ & $385 \mathrm{Vdc}$ \\
\hline Battery current & $I_{\mathrm{LS} 2}^{*}$ & $5 \mathrm{Adc}$ \\
\hline Internal resistance of battery & $r$ & $72 \mathrm{~m} \Omega$ \\
\hline Switching frequency & $f_{\mathrm{SW}}$ & $12 \mathrm{kHz}$ \\
\hline Dead time & $T_{\mathrm{d}}$ & $3.5 \mu \mathrm{s}$ \\
\hline
\end{tabular}

Unbalanced ratio $=\frac{S_{1}-S_{2}}{S_{\mathrm{A}} \times 0.5} \times 100[\%], \cdots \cdots$

where $S_{1}$ is the apparent power of Load1 in Feeder1, and $S_{2}$ is the apparent power of Load 2 on Feeder2. $S_{\mathrm{A}}$ is the total apparent power, which is the sum of the apparent powers $S_{1}$ and $S_{2}$ on Feeder1 and Feeder2, respectively. According to the Japanese guidelines for personal power use, the unbalanced ratio should be less than $40 \%$ for domestic power consumption $^{(26)}$. Thus, Load1 of 1.2 pu is connected in Feeder1, where the PF is 0.85 , and the total harmonic distortion (THD) value is $22.5 \%$. Load2 of 0.8 pu connected in Feeder2, where the $\mathrm{PF}$ is 0.87 , and the THD value is $20.9 \%$. Table 1 shows the circuit constants for Fig. 3, which were used in the following simulation results. $K_{\mathrm{P}}=0.8, T_{\mathrm{I}}=2.4 \mathrm{~ms}$ and $T_{\mathrm{D}}=0.6 \mathrm{~ms}$ were used in the PID controller for constant dc-capacitor voltage control, and $K_{\mathrm{P}}=0.04$ and $T_{\mathrm{I}}=8 \mathrm{~ms}$ were used in the PI controllers for the current feedback control in $d-q$ coordinates in Fig. 3 in the following simulation results. $K_{\mathrm{P}}=0.15$ and $T_{\mathrm{I}}=3 \mathrm{~ms}$ were used in the PI controllers for the current feedback control of the bidirectional dc-dc converter in the following simulation results. These values of control parameters were determined with ZieglerNichols ultimate sensitivity method and subsequently improved using digital computer simulation.

Figure 4 shows the simulation results for Fig. 3, where the proposed smart charger charges the battery with constant battery current control. $v_{\mathrm{S}}$ is the source voltage, and $v_{\mathrm{L} 1}$ and $v_{\mathrm{L} 2}$ are the secondary-side voltage waveforms; $i_{\mathrm{S} 1}$ and $i_{\mathrm{S} 2}$ are the secondary-side current waveforms; $i_{\mathrm{L} 1}$ and $i_{\mathrm{L} 2}$ are the loadside current waveforms of the domestic consumer; $i_{\mathrm{C} 1}, i_{\mathrm{C} 2}$, and $i_{\mathrm{C} 3}$ are the output current waveforms of the smart charger; $v_{\text {DC }}$ is the dc-capacitor voltage waveform; and $i_{\text {bat }}$ is the battery current waveform. Although the load currents $i_{\mathrm{L} 1}$ and $i_{\mathrm{L} 2}$ are unbalanced and heavily distorted, the source currents $i_{\mathrm{S} 1}$ and $i_{\mathrm{S} 2}$ are balanced and sinusoidal with a unity PF. The THD values of $i_{\mathrm{S} 1}$ and $i_{\mathrm{S} 2}$ are $4.6 \%$ and $3.3 \%$ respectively, under the steady state, and the voltage ripple of $v_{\mathrm{DC}}$ is $1.2 \%$.

Figure 5 shows the simulation results for Fig. 3, where the proposed smart charger discharges the battery with constant battery current control. Although the load currents $i_{\mathrm{L} 1}$ and $i_{\mathrm{L} 2}$ 


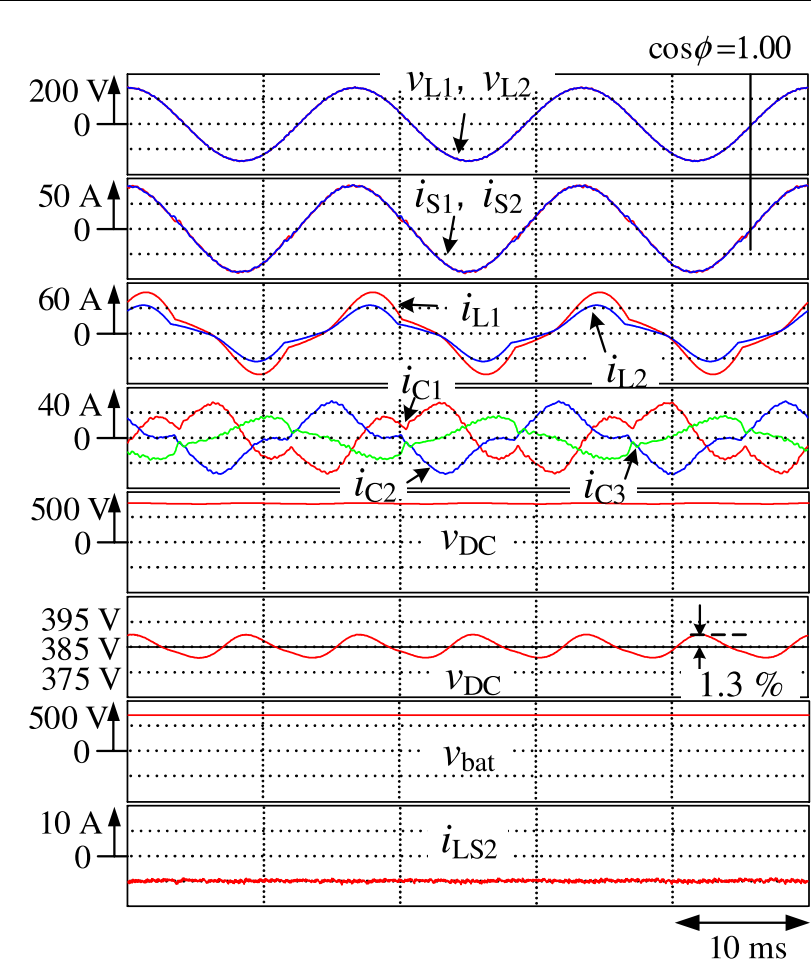

Fig. 4. Simulation results for Fig. 3 during batterycharging operation

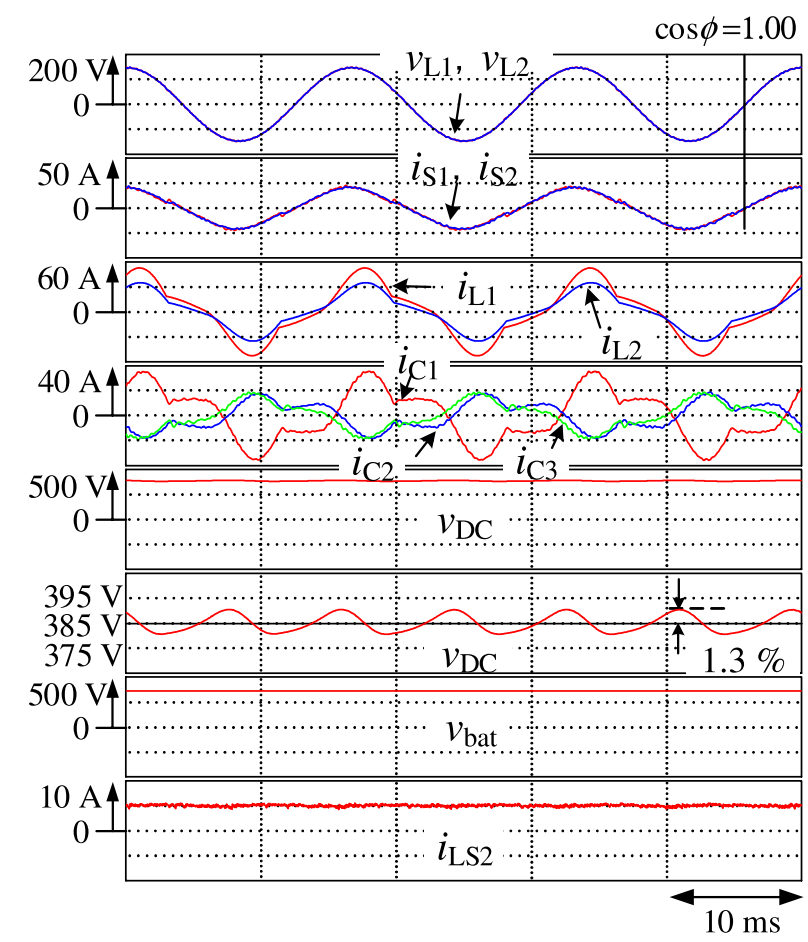

Fig. 5. Simulation results for Fig. 3 during batterydischarging operation

are unbalanced and heavily distorted, the source currents $i_{\mathrm{S} 1}$ and $i_{\mathrm{S} 2}$ are balanced with a unity PF. The THD values of $i_{\mathrm{S} 1}$ and $i_{\mathrm{S} 2}$ are $12.6 \%$ and $9.8 \%$, respectively, under the steady state, and the voltage ripple of $v_{\mathrm{DC}}$ is $1.2 \%$. The simulation results of Fig. 4 and Fig. 5 demonstrate that the balanced and sinusoidal source currents with a unity PF are achieved on the secondary side of the PMDT during both battery-charging and battery-discharging operations in EVs, compensating

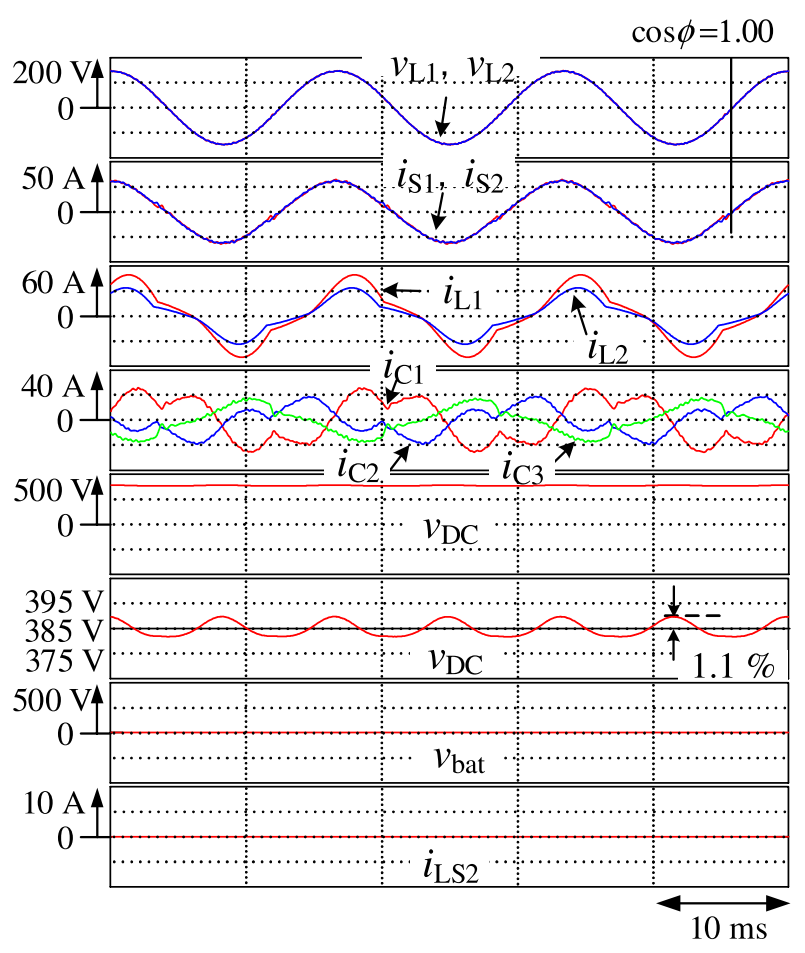

Fig. 6. Simulation results for Fig. 3 without battery, where smart charger performs active power-line conditioner

unbalanced active, reactive, and harmonic currents even though the load currents are heavily distorted.

Figure 6 shows the simulation results for Fig. 3, where an $\mathrm{EV}$ is not connected to the proposed smart charger. Thus, the smart charger acts an active power-line conditioner for the domestic consumer. Although the load currents $i_{\mathrm{L} 1}$ and $i_{\mathrm{L} 2}$ are unbalanced and heavily distorted, the source currents $i_{\mathrm{S} 1}$ and $i_{\mathrm{S} 2}$ are balanced with a unity PF. The THD values of $i_{\mathrm{S} 1}$ and $i_{\mathrm{S} 2}$ are $6.6 \%$ and $5.3 \%$ respectively, under the steady state, and the voltage ripple of $v_{\mathrm{DC}}$ is $1.2 \%$. The THD values of $i_{\mathrm{S} 1}$ and $i_{\mathrm{S} 2}$ in Figs. 4, 5, and 6 satisfy the regulations ${ }^{(12)}$. Thus, the proposed smart charger can solve the power quality problems.

Figure 7 shows the simulation results for Fig. 3 under the battery-charging operation, where the battery voltage $V_{\text {bat }}$ is $300 \mathrm{Vdc}$. The simulation results of Fig. 7 demonstrate that the CDCVC-based strategy for the smart charger achieves the balanced and sinusoidal source currents $i_{\mathrm{S} 1}$ and $i_{\mathrm{S} 1}$ with a unity power factor even though the battery conditions are changed.

The required capacity of the three-leg PWM rectifier, which performs smart charger, is now discussed. A definition of apparent power is generally used to calculate the required capacity of the PWM rectifier. However, the third leg connected to the neutral line is grounded. The usual definition of apparent power is not applicable to the three-leg PWM rectifier. In ${ }^{(27)}$, the authors have defined a current capacity $A_{\mathrm{C}}$ for the smart charger with a PWM rectifier in single-phase three-wire feeders. $A_{\mathrm{C}}$ is given as

$$
A_{\mathrm{C}}=\frac{\sum_{n=1}^{3} I_{\mathrm{Cn}}}{2 I_{\mathrm{A}}} \mathrm{pu},
$$

where $I_{\mathrm{A}}$ is the rating of Feeder 1 and Feeder 2 currents. The 


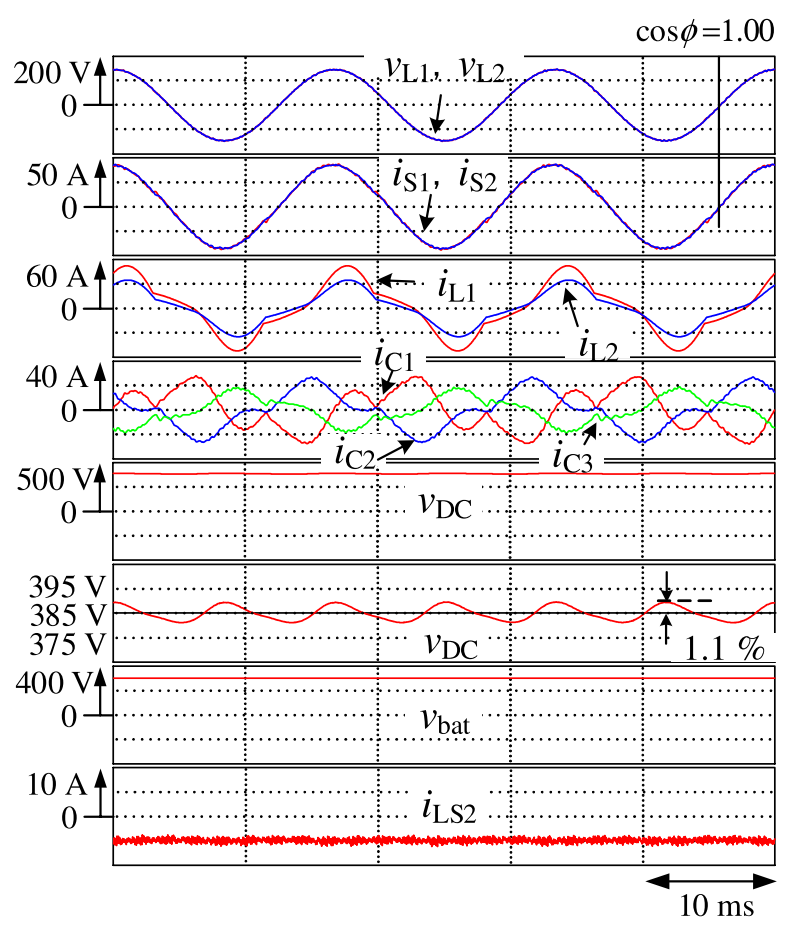

Fig. 7. Simulation results for Fig. 3 during batterycharging operation, where battery voltage is changed to $300 \mathrm{Vdc}$

rating of the PMDT is $6.6 \mathrm{kVrms}, 5.0 \mathrm{kVA}$, and $60 \mathrm{~Hz}$ on the primary side, and $105 \mathrm{Vrms}$ on the secondary side. Thus, $I_{\mathrm{A}}$ is 24 Arms. From the simulation results in Fig. 4, Fig. 5, and Fig. $6, A_{\mathrm{C}}$ are $0.87 \mathrm{pu}, 0.85 \mathrm{pu}$, and $0.74 \mathrm{pu}$, respectively.

\section{Experimental Results}

It is difficult to construct an experimental model with the actual voltage rating of the pole-mounted distribution transformer for the smart charger in Fig. 3 in the laboratory. A reduced-scale experimental model was thus constructed and tested to demonstrate the validity and high applicability of the proposed control method, which uses only constant dccapacitor voltage control for the smart charger. Figure 8 shows a block diagram of the constructed prototype experimental model. The ratings of the PMDT are $180 \mathrm{Vrms}$, $3.7 \mathrm{kVA}$, and $60 \mathrm{~Hz}$ on the primary side and $90 \mathrm{Vrms}$ and 20.6 Arms on the secondary side. Load 1 of 1.2 pu is connected in Feeder1, where the PF is 0.85 , and the THD value is $22.5 \%$. Load 2 of 0.8 pu is connected in Feeder2, where the PF is 0.87 , the THD value is $20.9 \%$, and the unbalanced ratio is $40 \%$. Table 2 shows the circuit constants for Fig. 8, which were used in the following experimental results. As shown (b), the charged power is consumed by a resistor $R$ of $60 \Omega$, which is connected in parallel to capacitor $C_{\mathrm{f} 2}$, during the battery-charging operation. The charged power is consumed by a $60 \Omega$ resistor $r$, which is connected in parallel to capacitor $C_{\mathrm{f} 2}$, during the battery-charging operation. For the battery-discharging operation, a dc power supply (Takasago: HX0300-25) and an internal resistance of the battery are connected to $C_{\mathrm{f} 2}$, where the voltage is $257 \mathrm{Vdc}$. The detected primary-side voltage $v_{\mathrm{S}}$, load currents $i_{\mathrm{L} 1}$ and $i_{\mathrm{L} 2}$, output currents of three-leg PWM rectifier $i_{1}$ and $i_{2}$, and dc-capacitor voltage $v_{\mathrm{DC}}$ are fed into a digital signal

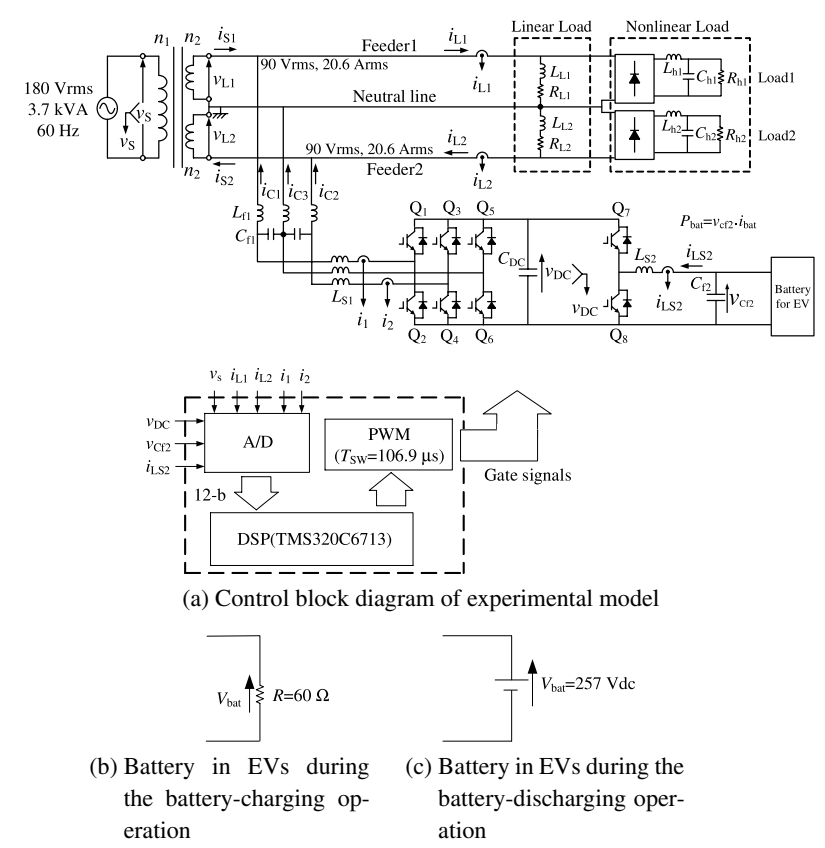

Fig. 8. Block diagram of constructed experimental model for smart charger in Fig. 3

Table 2. Circuit Constants for Fig. 8

\begin{tabular}{c|c|c}
\hline Item & Symbol & Value \\
\hline \hline Filter inductor & $L_{\mathrm{f}}$ & $0.46 \mathrm{mH}$ \\
\hline Filter capacitor & $C_{\mathrm{f}}$ & $10.4 \mu \mathrm{F}$ \\
\hline $\begin{array}{c}\text { Switching inductor } \\
\text { for three-leg inverter }\end{array}$ & $L_{\mathrm{S} 1}$ & $1.0 \mathrm{mH}$ \\
\hline dc capacitor & $C_{\mathrm{DC}}$ & $2700 \mu \mathrm{F}$ \\
\hline dc-capacitor voltage & $V_{\mathrm{DC}}^{*}$ & $360 \mathrm{Vdc}$ \\
\hline $\begin{array}{c}\text { Switching inductor } \\
\text { for dc-dc converter }\end{array}$ & $L_{\mathrm{S} 2}$ & $4.4 \mathrm{mH}$ \\
\hline $\begin{array}{c}\text { Filter capacitor } \\
\text { for dc-dc converter }\end{array}$ & $C_{\mathrm{f} 2}$ & $1000 \mu \mathrm{F}$ \\
\hline Battery voltage & $V_{\mathrm{bat}}$ & $257 \mathrm{Vdc}$ \\
\hline Battery current & $I_{\mathrm{LS} 2}^{*}$ & $4.2 \mathrm{Adc}$ \\
\hline Switching frequency & $f_{\mathrm{SW}}$ & $9.36 \mathrm{kHz}$ \\
\hline Dead time & $T_{\mathrm{d}}$ & $3.5 \mu \mathrm{s}$ \\
\hline
\end{tabular}

processor (DSP) (TMS320C6713, $225 \mathrm{MHz}$ ) through 12-bit A/D converters, where the sampling time $T_{\mathrm{S}}$ is $0.107 \mathrm{~ms}$. In the DSP, the reference values $i_{1}^{*}, i_{2}^{*}$, and $i_{3}^{*}$ for the three-leg PWM rectifier, which acts as a power quality compensator, are calculated by $(8)$. The output currents $i_{\mathrm{C} 1}, i_{\mathrm{C} 2}$, and $i_{\mathrm{C} 3}$ of the smart charger and the output current $i_{\mathrm{LS} 2}$ of the bidirectional dc-dc converter are also fed into the DSP through 12 bit A/D converters. The feedback control in $d-q$ coordinates for the single-phase circuits of Fig. 8 is used. This current feedback control was carried out in the DSP. In the experimental model, the circuit conditions shown in Table 2 were used. $K_{\mathrm{P}}=0.6$ and $T_{\mathrm{I}}=0.03 \mathrm{~s}$ were used in the PI controller for constant dc-capacitor voltage control in the experiment. $K_{\mathrm{P}}=0.06$ and $T_{\mathrm{I}}=8 \mathrm{~ms}$ were used in the PI controller for current feedback control in $d-q$ coordinates for the single-phase circuits in the experiment $K_{\mathrm{P}}=0.15$ and $T_{\mathrm{I}}=3 \mathrm{~ms}$ were used in the PI controller for the current feedback of the bidirectional dc-dc converter during both the battery-charging and 


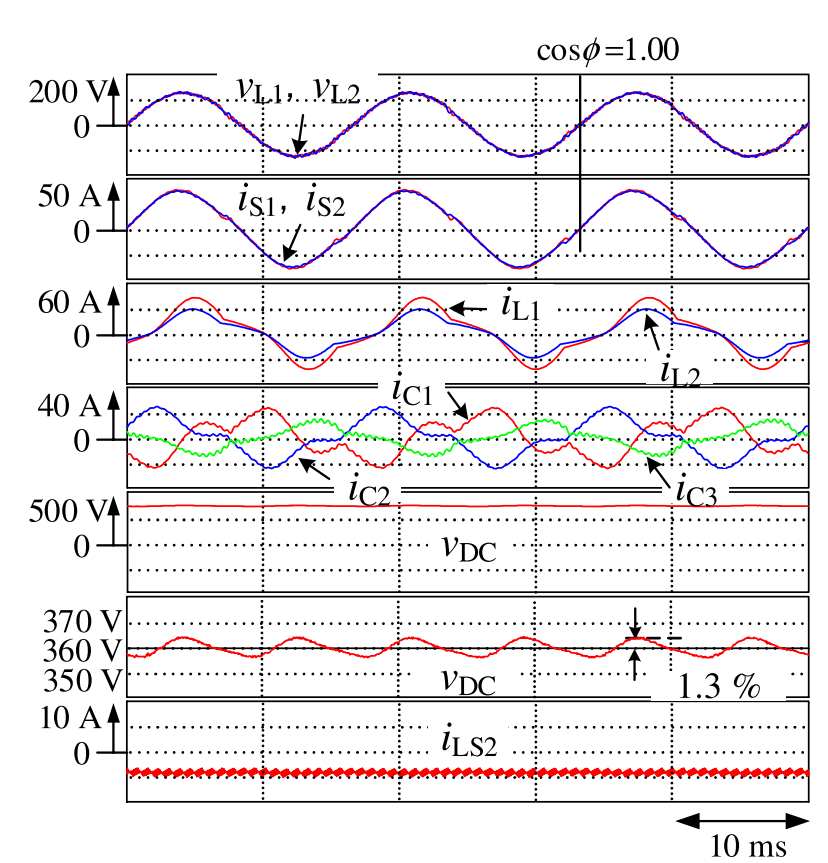

Fig. 9. Experimental waveforms for Fig. 8 during battery-charging operation

battery-discharging operations in the experiment.

Figure 9 shows the experimental results for the experimental model in Fig. 8, where the proposed smart charger charges the power in the battery using constant battery current control. As shown Fig. 8(b), the charged power is consumed by a resistor $R$ of $60 \Omega$. $\quad v_{\mathrm{S}}$ is the source voltage, and $v_{\mathrm{L} 1}$ and $v_{\mathrm{L} 2}$ are the secondary-side voltage waveforms; $i_{\mathrm{S} 1}$ and $i_{\mathrm{S} 2}$ are the secondary-side current waveforms; $i_{\mathrm{L} 1}$ and $i_{\mathrm{L} 2}$ are the load-side current waveforms of the domestic consumer; $i_{\mathrm{C} 1}$, $i_{\mathrm{C} 2}$, and $i_{\mathrm{C} 3}$ are the output current waveforms of the smart charger; $v_{\mathrm{DC}}$ is the dc-capacitor voltage waveform; and $i_{\mathrm{bat}}$ is the battery current waveform. Although the load currents $i_{\mathrm{L} 1}$ and $i_{\mathrm{L} 2}$ are unbalanced and heavily distorted, the source currents $i_{\mathrm{S} 1}$ and $i_{\mathrm{S} 2}$ are balanced and sinusoidal with a unity PF. The THD values of $i_{\mathrm{S} 1}$ and $i_{\mathrm{S} 2}$ are $7.49 \%$ and $5.13 \%$ respectively, under the steady state, and the voltage ripple of $v_{\mathrm{DC}}$ is $1.2 \%$.

Figure 10 shows the experimental results for the model in Fig. 8, where the proposed smart charger discharges the power from the battery $V_{\text {bat }}$, which is shown in Fig. 8(c), with constant battery current control with constant battery current control. Although the load currents $i_{\mathrm{L} 1}$ and $i_{\mathrm{L} 2}$ are unbalanced and heavily distorted, the source currents $i_{\mathrm{S} 1}$ and $i_{\mathrm{S} 2}$ are balanced and sinusoidal with a unity PF. The THD values of $i_{\mathrm{S} 1}$ and $i_{\mathrm{S} 2}$ are $17.0 \%$ and $10.2 \%$ respectively, under the steady state, and the voltage ripple of $v_{\mathrm{DC}}$ is $1.7 \%$.

Figure 11 shows the experimental results for the experimental model in Fig. 8, where the proposed smart charger without the battery with constant battery current control. Although the load currents $i_{\mathrm{L} 1}$ and $i_{\mathrm{L} 2}$ are unbalanced and heavily distorted, the source currents $i_{\mathrm{S} 1}$ and $i_{\mathrm{S} 2}$ are balanced and sinusoidal with a unity PF. The THD values of $i_{\mathrm{S} 1}$ and $i_{\mathrm{S} 2}$ are $9.8 \%$ and $5.6 \%$ respectively, under the steady state, and the voltage ripple of $v_{\mathrm{DC}}$ is $1.8 \%$.

From the experimental results in Figs. 9, 10, and $11 A_{\mathrm{C}}$ are $0.87 \mathrm{pu}, 0.82 \mathrm{pu}$, and $0.79 \mathrm{pu}$, respectively. The THD values

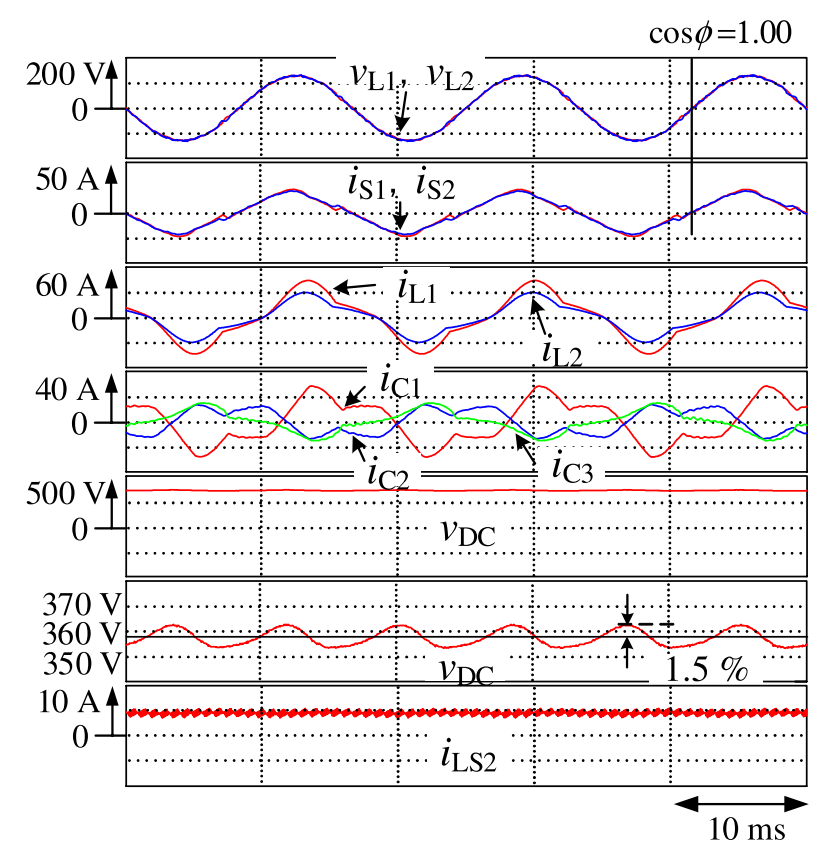

Fig. 10. Experimental waveforms for Fig. 8 during battery-discharging operation

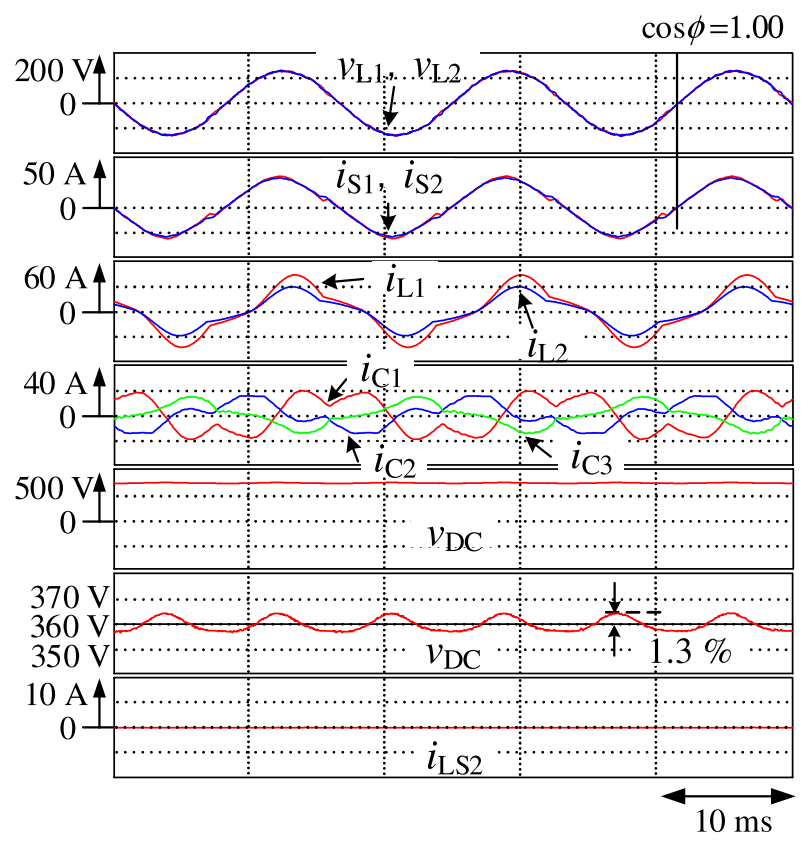

Fig. 11. Experimental waveforms for Fig. 8 without battery

of $i_{\mathrm{S} 1}$ and $i_{\mathrm{S} 2}$ in Figs. 9, 10, and 11 satisfy the regulations ${ }^{(12)}$. The experimental results of Figs. 9, 10, and 11 are in good agreement with the simulation results of Figs. 4, 5, and 6.

Figure 12 shows the simulation results with the experimental model of Fig. 8, where the proposed smart charger charges power in the battery using the constant current control. The circuit constants of Table 2 were used in the simulation results of Fig. 12. The charged power is also consumed by a resistor of $60 \Omega$. The experimental results of Fig. 9 agree well with the simulation results of Fig. 12. This indicates that the experimental results of Figs. 9, 10, and 11 are valid to demonstrate the validity and high practicability of the CDCVCbased strategy for the smart charger. 


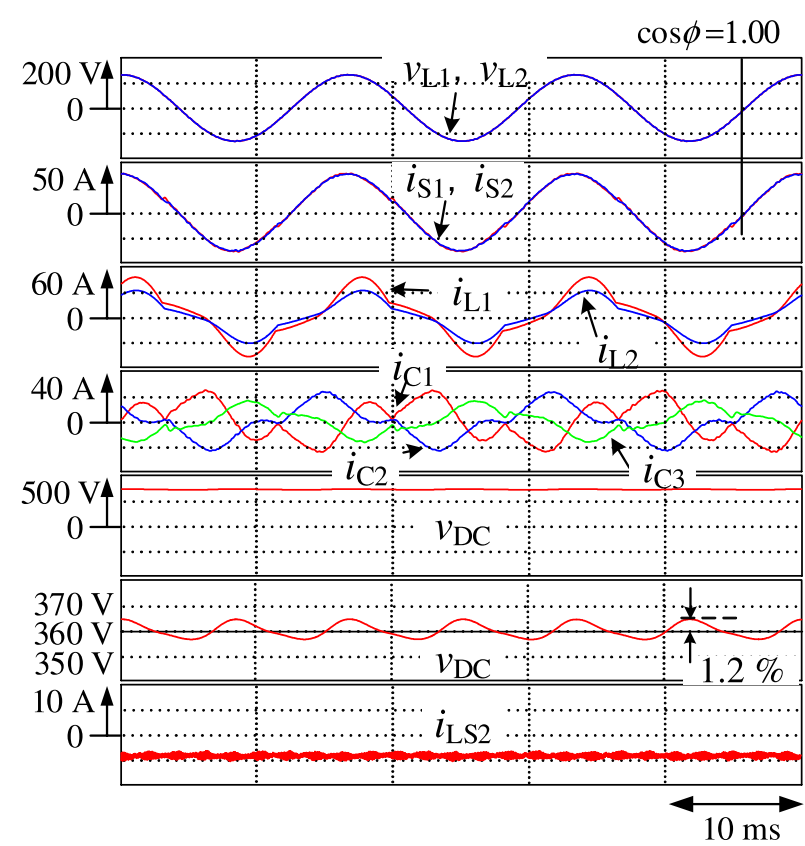

Fig. 12. Simulation results for smart charger during battery-charging operation with circuit constants of Table 2

\section{Conclusion}

This paper has presented reactive, unbalanced active, and harmonic currents compensation using the CDCVC- based strategy for the smart charger in SPTWDFs under distorted load current conditions. The basic principle of the previously proposed CDCVC-based strategy for smart chargers has been discussed in detail. The instantaneous power flowing into the smart charger has shown that the previously proposed CDCVC-based strategy can compensate fundamental reactive, unbalanced active, and harmonic currents on the source side. The balanced and sinusoidal source currents with a unity PF are achieved using only the CDCVC-based strategy, which is commonly used in active power-line conditioners. A digital computer simulation has been implemented to confirm the validity and high practicability of the CDCVCbased strategy under unbalanced and heavily distorted load current conditions. A reduced-scale prototype experimental model has been constructed and tested. Simulation and experimental results have demonstrated that balanced and sinusoidal source currents with a unity PF are achieved on the secondary side of the PMDT during both the battery-charging and battery-discharging operations in EVs, compensating the fundamental reactive, unbalanced active, and harmonic currents. Simulation and experimental results have also demonstrated that balanced and sinusoidal source currents with a unity PF are achieved even though EVs are not connected to the smart charger.

As described in Introduction, it is known that the unbalanced source-currents conditions increase losses in PMDTs. Balancing the currents in the two feeders is effective for balancing the feeder voltages and reducing the losses in the PMDTs. However, in this paper, no qualitative evaluations of loss reductions in the PMDTs have been shown. Qualitative evaluations on the loss reductions considering the conversion efficiency of the three-leg PWM rectifier are an important issue for further study. Thus, qualitative evaluations about the loss reductions will be reported in another article.

Finally, this paper is an improved and revised version of the conference paper ${ }^{(28)}$. The authors would like to express their gratitude to the audiences for their valuable discussions at the IEEE Energy Conversion Congress and Expo. (ECCE2015).

\section{References}

( 1 ) [Online] Available: http://www.meti.go.jp/committee/summary/0004668/ pdf/0120300. pdf (accessed on 10 January 2012.)

( 2 ) Y. Mitani: "Method and system for leveling power load", Japan Patent Office, 4862153 (P4 862 153), (Jan. 25, 2012)

( 3 ) [Online] Available: http://www.nissan-global/com/JP/NEWS/

(4) M. Yilmaz and P.T. Krein: "Review of benefits and challenges of Vehicle-toGrid technology", in Proc. of IEEE Energy Conversion Congress and Exposition (ECCE), pp.3082-3089 (2012)

( 5 ) I. Cvetkovic, T. Thacker, D. Dong, G. Francis, V. Podosinov, D. Boroyevich, F. Wang, R. Burgos, G. Skutt, and J. Lesko: "Future home uninterruptible renewable energy system with vehicle-to-grid technology", in Proc. of IEEE Energy Conversion Congress and Exposition (ECCE), pp.2675-2681 (2009)

( 6 ) Y. Gurkaynak and A. Khaligh: "Control and power management of a grid connected residential photovoltaic system with plug-in hybrid electric vehicle (PHEV) load", in Proc. of IEEE Energy Conversion Congress and Exposition (ECCE), pp.2086-2091 (2009)

( 7 ) V. Monteiro, J.G. Pinto, B. Exposto, H. Goncalves, J.C. Ferreira, C. Couto, and J.L. Afonso: "Assessment of a battery charger for electric vehicles with reactive power control", in Proc. of Ind. Electron. Conf. (IECON), pp.51245129 (2012)

( 8 ) M.C. Kisacikoglu, B. Ozpineci, and L.M. Tolbert: "Examination of a PHEV bidirectional charger system for V2G reactive power compensation", in Proc. of IEEE Appl. Power Electron. Conf. Expo., pp.458-465 (2010)

( 9 ) M.C. Kisacikoglu, B. Ozpineci, and L.M. Tolbert: "Reactive power operation analysis of a single-phase EV/PHEV bidirectional battery charger", in Proc. of 8th Int. Conf. Power Electron.-ECCE Asia, pp.585-591 (2011)

(10) T. Tanaka, T. Sekiya, H. Tanaka, E. Hiraki, and M. Okamoto: "Smart charger for electric vehicles with power quality compensator on single-phase threewire distribution feeders", IEEE Trans. Ind. Appl., Vol.49, No.6, pp.26282635 (2013)

(11) M. Uesugi, H. Kanazawa, A. Hiruma, H. Miyazaki, and T. Kanabe: "Singlephase Twice voltage PFC converter for air conditioner", IEEJ Trans. Ind. Appl., Vol.119, No.5, pp.592-598 (1999) (In Japanese)

(12) IEC61000-3-4, 1998

(13) H. Akagi, Y. Kanazawa, and A. Nabae: "Instantaneous reactive power compensators comprising switching devices without energy storage components", IEEE Trans. Ind. Appl., Vol.IA-20, No.3, pp.625-630 (1984)

(14) A. Nava-Segura and G. Mino-Aguilar: "Four-branches-inverter-based-activefilter for unbalanced 3-phase 4-wires electrical distribution systems", in Proc. of IEEE Ind. Appl. Conf., Vol.4, pp.2503-2508 (2000)

(15) F.Z. Peng, G.W. Ott, and D.J. Adams: "Harmonic and reactive power compensation based on the generalized instantaneous reactive power theory for the three-phase four-wire systems", IEEE Tran. on Power Electron., Vol.13, pp.1174-1181 (1998)

(16) B.N. Singh and P. Rast: "A new topology of active filter to correct powerfactor, compensate harmonics, reactive power and unbalance of three-phase four-wire loads", IEEE Appl. Power Electron. and Expo., Vol.1, pp.141-147 (2003)

(17) A. Adya, A.P. Mittal, and J.R.P. Gupta: "Modeling and control of DSTATCOM for three-phase, four-wire distribution systems", in Conf. Rec. of IEEEIAS Ann. Meeting, Vol.4, pp.2428-2434 (2005)

(18) N. Geddada, S.B. Karanki, M.K. Mishra, and B.K. Kumar: "Modified four leg DSTATCOM topology for compensation of unbalanced and nonlinear loads in three phase four wire system", in Proc. of EPE'11, pp.1-10 (2011)

(19) J.W. Dixon, J.J. Garcia, and L. Moran: "Control system for three-phase active power filter which simultaneously compensates power factor and unbalanced loads", IEEE Trans. on Ind. Electron., Vol.42, pp.636-641 (1995)

(20) A. Abllan, G. Garcera, M. Pascual, and E. Figueres: "A new current controller applied to four-branch inverter shunt active filters with UPF control method", in Proc. of IEEE Power Electronics Specialist Conference (PESC), Vol.3, pp.1402-1407 (2001)

(21) M.T. Haque: "Single-phase pq theory for active filters", in Proc. of IEEE TRNCON, Vol.3, pp.1941-1944 (2002) 
(22) L.N. Arruda, S.M. Silva, and B.J. C. Filho: "PLL structures for utility connected systems", in Conf. Record of IEEE-IAS Annual Meeting, pp.26552660 (2001)

(23) S.M. Silva, B.M. Lopes, B.J.C. Filho, R.P. Campana, and W.C. Boaventura: "Performance evaluation of PLL algorithms for single-phase grid-connected systems", in Conf. Record of IEEE-IAS Annual Meeting, pp.2259-2263 (2004)

(24) R.S. Zhang and C. Park: "Control of single-phase power converter in $d-q$ coordinates", United States Patent, Patent No. 6,621,252 (2003)

(25) M. Saitou and T. Shimizu: "A control method of single phase power active filter on $d$ - $q$ Coordinate with Hilbert Transformer", IEEJ Trans. IA, Vol.122, No.2, pp.193-194 (2002) (in Japanese)

(26) Japan electric association, indoor wiring guidelines, JESC E0005, p.32 (2005) (in Japanese)

(27) H. Tanaka, T. Wakimoto, T. Tanaka, M. Okamoto, and E. Hiraki: "Reducing capacity of smart charger for electric vehicles on single-phase three-wire distribution feeders with reactive power control", IEEJ Journal of Ind. Appl., Vol.3, No.6, pp.43744-5 (2014)

(28) T. Tanaka, F. Ikeda, H. Tanaka, H. Yamada, and M. Okamoto: "Novel simple harmonics compensation method for smart charger with constant dccapacitor voltage control for electric vehicles on single-phase three-wire distribution feeders", Proc. of IEEE Energy Conversion Congress and Expo. (ECCE2015), pp.5411-5416 (2015)

Fuka Ikeda (Member) received the M.E. and Ph.D. degrees in elec-

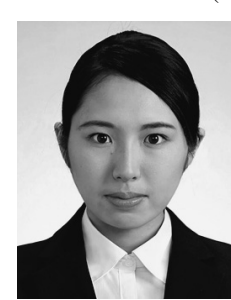
trical engineering from Yamaguchi University, Yamaguchi, Japan, in 2016 and 2018, respectively. Since 2018, she has been an Assistant Professor in the Department of Electrical Engineering at National Institute of Technology, Ube College. Her research interests are on smart charger for electric vehicles with power quality compensator in single-phase three-wire distribution feeders. Dr. Ikeda is a member of the IEEE.
Toshihiko Tanaka (Fellow) was born in Hokkaido, Japan, 1959. He

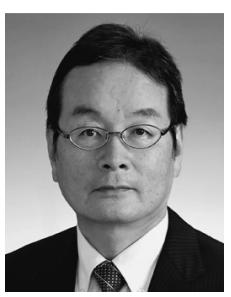
received the M.S. degree from Nagaoka University of Technology in 1984. In 1995, he received the Ph.D. degree from Okayama University. He joined Toyo Denki Mfg. Co. in 1984. From 1991 to 1997, he was an Assistant Professor at the Polytechnic University of Japan. From 1997 to 2004 he was an Associate Professor at Shimane University. Since 2004, he has been a Professor in the Department of Electrical and Electronic Engineering at Yamaguchi University. His research interests are on harmonics generated by static power converters and their compensation. Dr. Tanaka is a member of the IEEE.

Hiroaki Yamada (Member) received the M.E. degree from Shimane

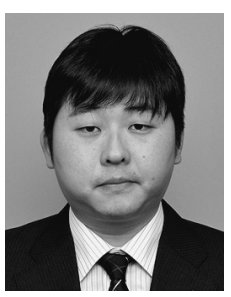
University in 2004. In 2007, he received the Doctor of Engineering from Yamaguchi University (YU). From 2007 to 2010, he was an Lecturer at Kushiro National College of Technology. From 2010 to 2014, he was an Assistant Professor at Kyushu Institute of Technology. Since 2014, he has been a Lecturer in the Department of Electrical and Electronic Engineering at YU. His research interests are on drawback current a member of the IEEE. compensation and LED power supply. Dr. Yamada is

Masayuki Okamoto (Member) received the M.E. and Ph.D. degrees

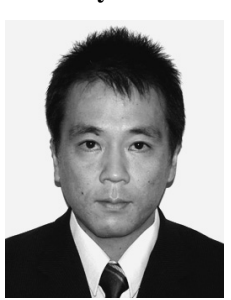
in electrical engineering from Yamaguchi University (YU) in 1996 and 1999, respectively. From 1999 to 2012, he was an Assistant Professor at YU. From 2012 to 2017, he was an Associate Professor at National Institute of Technology, Ube College. He is currently a Professor. His research interests include device modeling of GaN-based switching devices and design of high-frequency power electronic converters with the switching devices. Dr. Okamoto is a member of the IEEE. 